\title{
RESEARCH INTO LABOUR, EMPLOYMENT AND WORK IN NEW ZEALAND: OVERVIEW OF THE NINTH CONFERENCE
}

\author{
Philip S. Morrison \\ Institute of Geography, \\ Victoria University of Wellington
}

Each new conference in this series produces research which advances the field, often in unexpected directions. The ninth conference began by focussing our attention on two rapidly growing areas of labour market research: the dynamics of the labour market and its geography. Interest by New Zealand researchers in both these areas has been stimulated largely by the policy direction of the present Labour government. Research in these areas has also been stimulated by developments in data collection and computer software: the study of the dynamics by the release of panel data and longitudinal surveys, and the study of the geography by developments in Geographic Information Systems (GIS). In both areas the research has been driven by the need to move beyond analysis of the labour market in general, to the experiences of particular cohorts of individuals and particular local labour markets. Both have become important for putting in place policy intitiatives that are increasingly sensitive to client and community needs.

While research on labour market dynamics and geography was a significant feature of the ninth conference, our understanding of labour, employment and work (LEW) was advanced in other directions as well. The experience of women in the labour force, the role of community institutions in employment generation, the potential impacts of aging on the labour market and, for the first time in the LEW series, the employment experience of Pacific Island peoples in New Zealand. Notable also was the attention paid to health and safety issues, particularly those associated with work stress and mental health. Managing the work force continues to be a major research area, and in this conference papers addressed topics ranging from problems in small businesses through to corporate behaviour, including the public sector's own attempts to evaluate their employment programs. There is little doubt that research within government departments is not only being expanded in terms of staff and resources but is also being placed on a more professional footing. This has been accompanied by widespread dissemination of working papers through the internet which allows outsiders much greater involvement in contemporary debates. This welcome development is increasingly being reciprocated as more university research becomes available online. The result is a growing complementarity across the various research environments: the academy, private research institutions, government, and individuals.
The following overview offers a synopsis of the key arguents in each of the 35 papers under the 12 headings given in the contents.

\section{Recent Developments}

Patrick Conway and Nick Carroll from the Labour Market Policy Group (LMPG) of the Department of Labour began the conference by updating developments in the New Zealand labour market. They noted that employment growth was particularly strong over the $1993-2000$ period, causing unemployment rates to fall and labour force participation rates to rise. The continued shift to services and part-time work and the rationalization of the workforce were accompanied by a shift in the distribution of hours of work. The number of people working short hours (in all jobs) and the number working very long hours have both increased, lowering the proportion working the 'standard working week'. Addressing a matter of ongoing concern in an increasingly open economy Conway and Carroll also showed how skill shortages have tended to move inversely to the unemployment rate: when unemployment is low, participation is high and the shortage of skilled workers becomes acute. This problem appears to have worsened since the last conference in November 1998 and constitutes a major challenge to contemporary policy makers. As the last paper in this volume indicates, the supply and demand of skills has now become a research priority in LMPG.

\section{Structural shifts in the labour market}

The two papers in this section identified what we might call structural shifts in the New Zealand labour market. The first addresses the extent to which returns have shifted from labour to capital since the early 1980 s. The second addresses the extent to which trade liberalisation has altered the structure of our domestic wage structure. Both trends suggest the drivers of the New Zealand labour market are shifting away from the domestic to an increasingly influential global economy. '

In his paper on the factor shares debate, Geoff Bertram reminds us that the division of the national product between capital and labour is an old topic in economic theory but that in New Zealand in recent years it has become harder to track trends in labour's share because the national accounts 
are no longer prepared on an income basis. The question Bertram asks is: did the 1984 election mark the end of a long period of relative gain for labour at the expense of capital? His paper is motivated by the lack of clear evidence on the effect of the ECA and the possibility that any shift in the balance of power from labour to capital may in fact have been part of an economy-wide sea change in the balance of social forces since the early 1980s. While the evidence would appear to support the notion that the following two decades were associated with relative gains to capital, Bertram emphasises the care necessary in drawing such a conclusion. Of note is the role now being played by foreign capital, and the possibility that the rising share of profits captured by foreign interests could be squeezing the economic surplus accruing to domestic owners. This may make economic growth increasingly dependent upon the willingness of foreign interests to plough profits back into New Zealand in preference to alternative opportunities in the global economy.

Globalisation is also a major theme in the second paper. In one of the first explicit attempts in New Zealand to measure the relationship between trade liberalisation and labour market outcome, Stephen Blumenfeld, Aaron Crawford, and Pat Walsh explore the connection between our international competitiveness and labour market outcomes in manufacturing over the 21-year period, 1978 - 1998. In contrast to the former arbitration system which mediated the impacts of New Zealand's participation in the international economy, liberalisation of international trade and the domestic labour market opened up the economy to the full force of globalisation. Using data from 12 manufacturing industries the authors regress the log of total hourly earnings in manufacturing on import penetration and export intensity, controlling for a range of other variables. While import intensity appears to have had little impact on wages, export intensity does appear to have raised earnings- a result consistent with the standard trade theory. The negative coefficient on interaction with the ECA variable is interpreted to mean that after the ECA, workers were no longer able to capture rents accruing from exports - a result which may be consistent with Bertram's concerns over the proportion of the surpluses being expropriated by foreign capital.

\section{Dynamics}

Increasingly in New Zealand we are realising that policyoriented research can be enhanced by tracing the experience of individuals over time. In the first of two examples, Deborah Ball and Moira Wilson ask whether changes in benefit receipts increase labour market penetration. The study covers all people who received the DPB between 1993 and 1999 - over 30,000 each year. Their paper examines what happens to the earnings of successive cohorts of single parent DPB recipients as they are offered improved financial incentives, notably when they accept part-time and later full-time employment. The aim of this policy initiative was to improve beneficiaries chances of securing paid work thereby gradually reducing their dependence on the DPB.
By using multiple cohorts, Wilson and Ball are able to control for the changing composition of the population. Although they admit some likely influence of improved employment opportunities over the period, as well as a number of other uncontrolled factors, they find that large changes in the propensity to declare earnings from part-time work did follow the reforms. The links to full-time employment were less clear but were still suggestive of expected positive effects of financial incentives.

In their paper on unemployment dynamics Maria Gobbi and David Rea also illustrate the benefits of being able to trace the labour market experience of individuals over time. Their research draws on administrative information previously collected by the New Zealand Employment Service (NZES) - a unit record data set of the experiences of job seekers who were registered as unemployed from October 1988 to December 1997. Focusing on the 1993 cohort who were either registered as unemployed in 1993 or left the register in that year, Gobbi and Rea traced durations on the register, repeat spells, and total accumulated spells for different categories of unemployed over a four-year period. One of the advantages of individual records is that they remind us of just how variable individuals can be. For a quarter of job seekers, unemployment was a single, relatively brief experience but for the quarter at the other end of the spectrum unemployment was either a chronic or a recurring experience. Perhaps the most revealing finding was the observation that slightly more than one-third of the workingage population who were resident in New Zealand experienced unemployment at some time during the nine- year study period. Far from being confined to a small minority, unemployment seems to have been much more widespread in any given year than many analysts would have predicted. Further scope for analysis of dynamics is outlined later in this volume by Janette Briggs who discusses the new longitudinal survey of income, employment, and family dynamics.

\section{Labour market geography}

The next two papers mark an extension of Treasury's research into economic geography. ${ }^{2}$ Their contribution lies in their linking of recent theoretical ideas on patterns of labour adjustment in the New Zealand labour market with the country's geography, using a variety of scales. In their first scoping paper, Dave Mare and Wai-Kin Choy confront the fact that attempts to improve the employment prospects of people in particular regions may be confounded if the migration response is large - either inwards (in which case local people could be outbid for jobs by those arriving from elsewhere) or outwards as depressed areas lose their most able workers to other regions.

In his second paper, with Jason Timmins, Dave Mare reports the associated empirical work on patterns of interregional migration between 1986-91 and 1991-96. Together the authors construct a range of labour-market indicators for each region and relate them to measures of movement of people between the regions. They then assess the absolute 
and relative importance of each indicator in terms of statistically explaining migration patterns. As well as drawing on a more explicit theoretical framework, their paper departs from previous migration studies in New Zealand by also explicitly integrating international migration as part of the labour adjustment process. They define regional adjustment as restoration of long-term relativities between regions following a (positive or negative) 'shock' to one or more regions. In such a conceptualization it is the path and the speed of the convergence towards these long-term relativities which is of interest. While their results do suggest there are sustained differences in adjustment between different spatial units, these differences could also indicate very slow adjustment of highly divergent regions.

The third paper on labour market geography asks whether individuals in different regions vary in the probability of their movement between employment, joblessness, and being outside the labour force. Philip Morrison and Olga Beresovsky show how these probabilities vary systematically by the size of labour market and the level of labour demand in the region. By drawing on the gross flows data of males from the Household Labour Force Survey over the 53 quarters between 1986 through 1999 , they show how individuals in different regions vary in the likelihood of moving between different states in the labour market (after controlling for secular, cyclical and seasonal effects). Their main finding concerns the relationship between local labour market conditions and job search behaviour. They argue that, contrary to the discouraged worker hypothesis, employment insecurity in the smaller regions actually increases the pressure on unemployed men to actively search for new work. In contrast, the greater chance of securing work in metropolitan centers allows men leaving employment to take a more relaxed attitude, as indicated by their greater propensity to temporarily withdraw from the labour force. The net effect is to widen unemployment disparities across the regions by raising the proportion of men searching for work in depressed regions while reducing that fraction in buoyant regions.

\section{Women in the labour force}

As in the previous eight LEW conferences gender issues continue to attract innovative research. Prue Hyman suggests that the police force might (but might not) be the last bastion of male hegemony. Extensive interviews make it clear that the exposure to danger and fitness/physique requirements, along with related macho behaviours and camaraderie, are linked to societal attitudes which previously excluded women and still provide a setting which is alienating for many women. Furthermore, restructuring and tight resources have made staff flexibility and use of fractional appointments more difficult. Hyman raises the possibility that in such an environment part-time and EEO positions may be squeezed in a manner that indirectly discriminates against women. At the same time, trends in the police make it increasingly critical for efficiency reasons to ensure it conserves zealously its female human capital.
In exploring pressures of a different kind, Janet Bedggood develops the idea that women in the teaching profession perceive their vulnerability to increased pressures in the workplace in much the same way they view their role as domestic labour. Bedggood considers the idea that struggles against the labour reforms reflect a struggle to overcome the dominant perceptions that care-giving is 'merely' an extension of domestic work. This hypothesis is explored through interviews with women teachers in the early childhood sector. The flattening of state funding appears to have exploited women's role of caring for children by blurring the distinction between care and education. In order to underscore both the nature of the vulnerability and the essential problem, Bedggood documents the way in which women manage dual expectations of themselves, family and work responsibilities.

One sector of the economy in which women have increased both their absolute and relative numbers is in the 'information workforce' where in 1996 they made up 55 percent of the female workforce. Hans-Jurgen Engelbrecht suggests that the economic reforms have led to a dramatic restructuring of the country's information workforce since 1984. While New Zealand has caught up to the US in the proportion of women employed in that sector, our patchy productivity growth and weak national information systems raise questions about the meaning of the term 'knowledge economy'. Indeed, it is possible that in New Zealand much of the 'knowledge economy' may lie outside high productivity, high wages, and high technology sector. Engelbrecht's main concern, however, is with documenting the relative importance of females as information workers. Even though fulltime information occupations make up a larger proportion of total number of women in full-time employment, high- skilled workers make up a relatively larger proportion of the male workforce. At the same time, the high-skilled component of both men and women rose from 13.6 percent to 23.7 percent between 1976 and 1996 in a general upskilling of the information workforce.

Although not confined to women, many of the factors associated with the time spent in unpaid work are closely related to the contemporary and varied position of women in the labour force. In their Ministry of Women's Affairs funded study, Suzie Carson, Frances Krsinich, and Susan Kell identified those factors which help explain the statistical variation in hours of paid work undertaken by a sample of 8522 men and women over a 48-hour period between July 1998 and June 1999. This project, conducted by Statistics New Zealand under contract to Ministry of Maori Affairs, identified the labour force status, age group, and days of the week as significant predictors of work hours. Interestingly, neither the number of children nor the age of the youngest child were significant predictors of the time mothers devoted to paid work. Furthermore, the number of children was not important in predicting the amount of time women devoted to unpaid work, even though age was a significant factor in raising the number of hours worked by both men and women. 
While not confined to the experience of women, Avette Kelly's study of work/life balance programs also speaks to the situation faced by many women in the workforce. With up to a quarter of women aged 18-35 in the US and Europe saying they do not intend to have children, the question arises as to how family-centred workplace programmes are being viewed by women without families. The aim of this research is to gauge the reaction of such women. E-mail questionnaires were sent to a non-random sample of childless employees from the Auckland City Council and 10 other firms. Kelly found no evidence that women without children felt disadvantaged by familyfriendly initiatives, especially where the programmes themselves were flexible and could be used by anyone who needed them. Most felt that programmes were available to women without young families or children should they need them and that initiatives that allowed people to balance their work and home lives should be encouraged. There was an agreement, however, that promoting programmes as worklife rather than family-friendly initiatives probably contributed to these positive New Zealand findings. The paper calls for a greater awareness of the need for balance in the promotion of such subcultures.

\section{Community institutions}

Increasingly governments are seeking to promote programmes which will address the employment shortfalls among vulnerable members of the workforce. Three papers delivered at LEW9 address this issue. Allen Bartley, Anne de Bruin, and Ann Dupuis outline the Department of Labour's Human Capability Framework (HCF). This framework makes a distinction between the capacity of individuals to undertake paid work and the opportunities to do so and recognises that both are mediated by their social and institutional contexts. The authors use this framework to examine the effectiveness of training in matching capacity with opportunity in particular macro economic and regional conditions. Of specific interest is the way agencies such as Skill New Zealand channel the flow of information that precedes effective matching, and how participants obtain their information about their local labour market: from whom, about what, and under what constraints. The empirical work starts to map these information flows in the Hawke's Bay. The authors report perceptions of the different agents involved, highlight their different agendas and priorities and document the difficulties in providing longterm employment.

As a way of extending her work on social capital (see LEW8) Anne de Bruin, together with Grant Power and Shayne Toko, introduce a new concept - positive spirals of societal capital. They use case studies to illustrate the need for community-level action as an immediate step towards 'closing the gaps'. The aim is to integrate community-controlled, third sector/civil society initiatives into a wider strategic perspective of development. Social capital is defined as the summation of infrastructure, plus human, intellectual and natural capital. Positive spirals of social capital take place when the capital is "harnessed and eth- nically invested to produce a positive return to society". The key driver is 'community energy', which is a cross between 'social energy' and 'cultural energy'. The process is one of empowerment - the enhancement of the individual and collective capacity to take or regain control over conditions determining well-being. Several empowering projects are then outlined. The authors also draw our attention to many other local initiatives which also deserve documentation.

\section{Aging}

Despite the growing numbers of older workers in the labour market only one of the papers in previous LEW conferences addressed this issue. ${ }^{3}$ Two papers in this conference help correct that deficiency. In the first, Grant Scobie looks ahead 50 years or so in order to explore the possible effects of aging on the savings rate. The paper explores the implications of future aging patterns for the government's budget, national savings levels, investment, the capital:labour ratio, wages, and interest rates. Of particular note are the much higher levels of dependency forecast for the 2020-40 period, even though these are offset by falls in the dependency levels of the very young. It is improbable, argues Scobie, that the projected rise in age dependency could be offset in any significant way through immigration. Scobie pays particular attention to the negative relationship between aging population and level of household savings, and examines the implications for investment and hence economic growth, firstly in a national then in an international context invoking a 'young country -old country model'. One of his important points is that the projected decline in the growth rate of the labour force will reduce the overall rate of economic growth. A number of other conclusions which follow from that observation appear in the paper.

Continuing the focus on the long-term consequences of an aging population, Paul Callister and Dennis Rose question the implications of expected changes in the labour market on the sustainability of New Zealand Superannuation. In particular they explore the way in which the balance between market and non-market work and leisure is going to be affected by the demands of an aging population. Unlike some in the literature they do not foresee a long-term historical decline in male participation rates, arguing that pressures to employ older men are likely to rise as labour demand faces a slower growing labour supply. At the same time they find little within their model to suggest that higher participation rates or wage rates will in fact solve New Zealand's emerging superannuation problem.

\section{Employment outcomes for Maori and Pacific peoples}

This conference continued its reputation for bringing new findings on Maori and the labour market to the research community, this time with a study of Maori literacy. Simon Chapple focuses on the links between Maori ethnicity, literacy, employment prospects, and levels of earnings 
noting in particular the high correlation between low scores on literacy and an inability to secure paid work. This builds on his previous paper presented at LEW8. ${ }^{4}$ The problem, argues Chapple, is "not that there are no explanations for the observed facts; rather the problem is that there are too many explanations and one cannot readily distinguish between them using currently available information." One important point is clear however - very little of the earnings differential is explained statistically by knowing whether the respondent is Maori ( $<1$ percent). Adding age and marital status reduces the earnings gap of both men and women by approximately one-third and adding education cuts it further, and adding literacy reduces the gap even further but much is still left unexplained. We do learn, however, that the gap in employment chances of Maori as opposed to non-Maori only exists for sole Maori (those with only Maori ancestry) but not mixed Maori.

In one of the first papers in New Zealand to explicitly address the determinants of employment among Pacific Island peoples, Janet Humphris and Simon Chapple explore the possible reasons why the disparity in labour market outcomes between Pacific and non-Pacific peoples widened substantially between 1985 and 1999 . Focusing on the disparity in employment rates, the authors suggest that one of the main reasons for the increase in the disparity was the over-representation of Pacific people in sectors such as manufacturing that were disproportionately affected by changes in labour demand in the late 1980 s. The significance of this paper is not this conclusion per se - which has been reached in numerous other studies - but that it confirms this result using an appropriately specified multivariate model which controls for other competing factors.

\section{Health and Safety}

Health and safety issues were the subject of four papers at LEW9. Kevin Dew explored the process of seeking compensation for occupational illness under a no-fault accident insurance scheme. He used case studies of firefighters and timbermill workers exposed to risks to illustrate how science can be used to deny compensation to sick and dying workers. Most importantly he shows how science can be co-opted and used to support business and state interests against workers and how ideological support can be hidden behind apparently 'objective' systems of assessing compensation claims.

Mike Lloyd considers the way in which workplace $\mathrm{cul}$ tures can affect the level of health and safety in the workplace. Using material from the recent ministerial inquiry into workplace injuries and fatalities at Tranz Rail, Lloyd considers whether any culture or cultures within Tranz Rail affected the safety and health of the workplace. His discourse analysis suggests that the culture question is indeed important, but not quite in the areas suggested by some of the contributors to the Tranz Rail inquiry. Tranz Rail's submission highlighted the rigidity of its own culture, by invoking the TINA (there is no alternative) response to the culture problem. There are always alternatives, and what
Lloyd's paper does is highlight the significance of culture in understanding how they are perceived and what these perceptions mean for safety in the workplace.

In the first of two papers on the mental health aspects of paid work, Cathy Robertson and Felicity Lamm look for evidence linking poor management techniques to the mental ill-health of employees. They find sufficient evidence in a pilot study (eight people in service and specialist professions) to call for further research to establish and quantify the relationships. Robertson and Lamm place particular emphasis on stress and note how job unsuitability and poor human relations (particularly bullying) are contributing factors. This pilot study raises concerns about the types of management malpractices that exist, their negative health effects and resultant costs.

In her own paper Felicity Lamm begins by noting how the small-business sector has a higher incidence of injury and ill-health and lower occupational health and safety compliance rates than the medium-sized and large-business sectors. Based on data from 65 small businesses $(<20$ outside manufacturing and $<100$ in manufacturing) from 1990 onwards, Lamm shows how small businesses have difficulty in complying with and enforcing OHS regulations. This is largely for financial reasons, but also because of kin-based hiring inhibits the formalisation of OHS procedures and this is compounded by the presence of a high proportion of women and immigrants in small enterprises. Collectively these factors generate obligations to attend work in spite of ill-health or family circumstances and this in turn leads to higher on-the-job injury rates. Longer working hours and out-sourcing add to the complexity of the employment environment in which this study of absenteeism is set.

If stress can be deemed a mental ill-health issue then it may be that wider, structural developments within an industry can also play a contributing role. This thesis is elaborated by Jill Ovens and Derek McCormack who document the way in which academic staff in tertiary institutions repeatedly report being overworked and undervalued. At the same time recent changes in education provision and funding have meant that ensuring safe, equitable, and reasonable workloads is an increasingly difficult management task. The authors suggest several workload models as the basis for more constructive discussion between unions and management.

\section{Managing the workforce}

Since the inception of human resource management (HRM) as a formal discipline, much has been written about management styles and the employee/employer relationship. At the same time, HRM theoretical frames of reference have changed from a scientific approach to a more humanistic one. In his paper Tony Naidu reports on a pilot study which explores the complexities of managing a team in Telecom. Based on responses to a structured questionnaire, the results suggest that participative management, while being a popular and effective approach, also contains a number 
of pitfalls which this study identifies.

Also drawing on Telecom's experience, Peter Ross uses transaction cost and downsizing theory to explain why firms may choose to either out-source their transactions to the marketplace or to perform them in-house. The model is then applied to the downsizing of Telecom from 16,000 to approximately 7,500 workers between 1990 and 2000. Ross raises questions about the possible loss of core knowledge when such massive staff reductions are made, and he examines the subsequent coordination and monitoring of outsourced work. Ross suggests that while transactions cost theory is relevant, short-term profit considerations, the size of the New Zealand telecommunications industry, and Telecom's continued dominance of its domestic market and desire to form strategic alliances also had a noticeable role in the restructuring of that company. Theoretical models, he argued, need to be adjusted to take these contextual considerations into account.

In their paper Paul Hursthouse and Darl Kolb explore whether changing the site of production allows a company to develop alternative systems of staff values and beliefs. The comparison is between the two sites of the food processor Heinz-Wattie Australasia in Hastings - the Brownfield (King St) site (established 1934, with 452 current staff) and the Greenfield (Tomoana) site (established 1996, with current 43 staff). Greenfield sites were seen a way of capitalising on the options available within the new legislative environment (specifically the Employment Contracts Act 1991) as well as providing opportunities for innovation and experiment. The acquisition of the Tomoana site in 1995 led to a decision to try a new management style and a culture of excellence. Unlike the prescriptive, highly detailed contract at King St, the Tomoana agreement was largely a philosophical statement about employee participation and learningby-doing. Tomoana was run in small teams of flexible workers who could turn their hand to any task. Using a Likerttype scaled questionnaire, Hursthouse and Kolb assess the ways in which members of the two organisations thought and behaved in relation to their tasks and to other people. Their results showed that both attitudes and behaviour at the two sites were statistically different and concluded that there were indeed quite separate cultures operating.

In quite a different paper Rupert Tipples explores the role of contests in developing the industry workforce. Contests are competitions which demonstrate skill and the awards for which recognise accomplishment. Noting the usefulness of contests as a means of agricultural education and extension, Tipples examines their relation to the New Zealand psyche. He links contests back to the pioneering spirit of early farmers - men's success required individuality and toughness and an ability to take risk. Much of this cultural ethos, Tipples argues, still prevails. New Zealand occupies $17^{\text {th }}$ place in an international ranking of the prevalence of masculine culture (Japan is first and Sweden is last at 53rd). A second important feature of modern- day contests is the widespread and enduring participation of stakeholders who perceive commercial benefit, both short term and long term in their promotion. Tipples' study of five different contests shows that all stakeholders (including the government) had to benefit for a contest to have lasting value and it is this participation that has ensured the educational as well as commercial value of contests in the development of New Zealand agriculture.

The involvement of the state is also the thesis of a paper by David Mare. The New Zealand government spends $\$ 600$ million a year on improving the job prospects of poorly educated and disadvantaged job seekers in New Zealand and is required to monitor the impact of this intervention. Mare draws on the New Zealand employment service administration records to judge how government assistance affects their subsequent contrast with the New Zealand Employment Service. Mare develops a range of estimates to help distinguish the impact of programmes on employment outcomes from the effect of its selection of participants. A central problem in estimating the effect of the programmes is that people are not assigned randomly to the intervention. On the contrary, targeting has been characteristic of New Zealand's labour market policies, so that presence of selection effects in evaluations will be inevitable. Research therefore needs to be designed carefully to separate selection from assistance effects. Without this attention to the research design, outcomes may simply reflect the sample rather than the intervention.

\section{Labour statistics}

Much of the progress the New Zealand research community has made in understanding the workings of the domestic labour market has come from the provision of new data. This in turn has allowed theories and techniques used overseas to be applied in the New Zealand context. Statistics New Zealand plays an instrumental role in channelling the kinds of questions we ask and the type of research we undertake into its data funding programmes. In the spirit of this relationship the following two papers introduce additional data to students of labour, employment and work.

Judith Archibald reports on the New Zealand Income Survey (NZIS) which Statistics New Zealand runs annually as a supplement to the June quarter Household Labour Force Survey (HLFS). The advantages of this supplement are a much richer set of income data based on a much larger sample size than previously available. The NZIS provides data on income support, educational qualifications, and returns from the labour market, data from which researchers will be able to investigate the distribution of income and different groups of people by income source, examine the impact on income of various economic of social policies, and the impact on incomes of educational and work choices by individuals. The NZIS (and the HLFS on which it is based) has a much larger sample size than other SNZ household surveys (with the exception of the Population Census). Archibald provides a useful tabular comparison of the NZIS and the Household Expenditure Survey (HES), tax data, and the population census. 
As the papers on dynamics in Part 3 have already demonstrated, longitudinal surveys are transforming the way we conceptualise and measure the incidence of events and how we measure the impacts of policy intervention. In addition to clarifying the differences between panel and longitudinal surveys, Janette Brigg's report introduces the Longitudinal Survey of Income, Employment and Family Dynamics. This survey will provide hitherto unavailable information about the changes in the economic well-being of individuals and the factors that influence those changes, such as labour market behaviour and changes in family structure. From an initial panel of households, the individuals selected will be interviewed and reinterviewed once every 12 months for 8 years. Asset data will be collected at two yearly intervals.

\section{Research priorities}

David Turner from the Labour Market Policy Group (LMPG) shared his group's planned research and evaluation strategy. The primary purpose of the LMPG he explained is to carry out high-quality policy-relevant research and evaluation, and to provide quality assurance and peer review on research survey and policy work. Turner's report outlines the criteria for choosing research and evaluation projects (strategic importance, applicability and feasibility, utility, nature of intervention and risk management). The priorities for 2001/2 and beyond include employment-related skills and knowledge (in order to ensure that labour market considerations are adequately covered in training and policy discussion). Other priorities include non-wage conditions of employment, labour market adjustment (how it takes place, how we can anticipate the issues and how we can design policies to take account of the unevenness). Other areas of concern are disparities, inequalities in labour market outcomes - especially for particular sub-populations, and differing responses by individuals to otherwise similar conditions. Macro economy-labour market links and location and dynamics all feature as research areas in the 2001/2 scenario together with immigration research and the ongoing monitoring of the ECA.

\section{References}

Bedford, R. (2001) Reflections on the spatial odysseys of New Zealanders. Paper presented at the Third Joint Conference of the Institute of Australian Geographers and the New Zealand Geographical Society. University of Otago, Dunedin 29-Jan-2 Feb 2001. Published in New Zealand Geographer 57(1): 29-54

Bushnell, P and Choy, W.K. (2001) 'Go west, young man, go west' Briefing Paper No 6, The Treasury, Wellington. Paper prepared for the seminar "Strategic responses to integration pressures: lessons from around the world" Harvard University, 29-30 March 2001. Published as Treasury Working Paper 01/07. http:// www.treasury.govt.nz/workingpapers/2000/default.asp
Claridge, M. and V. Plater (2000) Facts about economic integration: how integrated is New Zealand with the rest of the world? Treasury Working Paper 00/21 http:/ /www.treasury.govt.nz/workingpapers/2000/default.asp

Claridge, M. and S. Box (2000) Economic integration, sovereignty and identity: New Zealand in the global economy Treasury Working Paper 00/22 http:// www.treasury.govt.nz/workingpapers/2000/default.asp

Department of Labour 2001 Workforce 2010: a document to inform public debate on the future of the labour market in New Zealand. Wellington: New Zealand Government

Easton, B. (2000) The London Economist and the New Zealand economy http://www.thevisiblehand.net

International Monetary Fund (2000)/New Zealand: selected issues. IMF Staff Country Report No. 00/140 Washington DC

Morrison, P.S. (2001a) “Employment." In Willis R. (ed.) New Zealand in the Nineties. A special issue of Asia Pacific Viewpoint 42(1): 85-106. http:// www.geo.vuw.ac.nz/staff/morrison.html

Morrison, P.S. (2001b) Labour market geography in a global context: notes on the New Zealand case. $2001 \mathrm{Ge}$ ography, a spatial odyssey. Proceedings of the joint New Zealand Geographical Society and the Institute of Australian Geography Joint Conference, 29 Jan - 2 Feb, 2001, Dunedin.

OECD (2000) Economic outlook. New Zealand OECD, Paris URL?

The Economist (2000): New Zealand examined December 2-8: 83-89

The Treasury (2001): Geography and the inclusive economy: a regional perspective Working Paper 01/17 http:// www.treasury.govt.nz/workingpapers/2001/

\section{Notes}

' Richard LeHeron raised this same point in his paper to LEW5 in 1992. Interest in this issue has gathered considerable momentum since then. Indicative are the two papers - Claridge and Plater (2000) and Claridge and Box (2000) - released on the Treasury web page shortly after the conclusion of this conference). Both constitute a valuable context within which to view the whole question of the impacts of globalisation on the New Zealand economy and society. Several other more recent reports are also relevant background to this debate: IMF (2000), OECD (2000), The Economist (2000), Easton (2000). Also see Morrison (2001a and b) and Bedford 2001, Bushnell and Choy (2001) and Workforce 2010 (Department of Labour).

${ }^{2}$ Six months or so after the conference the Treasury re- 
leased their own summary of this and related research in a paper entitled: Geography and the inclusive economy: a regional perspective, Working Paper 01/17.

${ }^{3}$ Tweedy and Johnson 'Mature employment and post-modern portfolio living' in LEW7 (1996: 141-147).

${ }^{4}$ S. Chapple and D. Rea 1999 Time series analysis of disparity between Maori and non-Maori labour market outcomes in the Household Labour Force Survey. In P.S. Morrison (ed.) Labour, employment and work in New Zealand 1998. Proceedings of the Eighth Conference. Victoria University of Wellington: 18-30. 